\title{
Tailoring methodological bricolage to investigate non-discretionary use of digital technology
}

\author{
Emilia Sobolewska \\ Edinburgh Napier University \\ School of Computing \\ 10 Colinton Rd, EH10 5DT \\ e.sobolewska@napier.ac.uk
}

\begin{abstract}
Digital technology appears to be an integral part of everyday life: at homes, workplaces, during leisure time; mediating interactions, demanding attention and engagement. In the age of cloud computing, social media, and ubiquitous mobile devices, it is easy to think that everyone appreciates its supposedly liberating effects. The question arises, whether it is possible to remain detached from what the digital technology has to offer, or is resistance futile? How do people cope with its unanticipated and sometimes involuntary use? The aim of the study was to create an engaged, first-hand, context dependent account of people's experiences with non-discretionary use of digital technology. In this scenario, people are required to change their everyday practices in order to accommodate use of digital devices. This paper aims to advocate benefits of methodological bricolage, where the researcher tailors tasks, tools, and approaches to understand the subject at hand. The investigation relied upon qualitative methods of data gathering, which enabled open and involved exploration, as well as interpretive methods to make sense of gathered information.
\end{abstract}

\section{Context, non-discretionary use, bricolage, qualitative research methods, IPA, research methodology.}

\section{INTRODUCTION}

The use of digital devices and access to the Internet bring a wide spectrum of benefits. Many products and services are easier and cheaper to access online. Examples include everyday goods, insurance deals, access to cultural events, and even dating. Online platforms, social networking sites, and applications afford instant communication. Public services are increasingly switching to online communication and information delivery. For example, the Department for Work and Pensions, the Home Office and the National Health Services already have well established Web presences that people have to engage with if they are to claim benefits or obtain other services. For some, digital technologies are associated with fun and pleasure, for others, who rely on wearable aids; they afford everyday, unrestricted functioning in society.

The Internet is just one instance of digital technology that is influencing people's everyday practices. Further examples include hardware (mobile phones, laptops, tablets); credit and debit cards, checkout machines, ticket machines and other devices. The use of software (for example MS Office, Adobe Cloud etc.) is similarly rarely a user's choice, but a decision that is forced upon them.

The benefits resulting from the use of digital technologies are numerous, and many people take advantage of them. However, there are some who do not take full advantage of these opportunities. For a number of them it is a matter of personal choice, whilst others were not given an opportunity, due to either lack of funds or lack of skills. In this paper particularly first category of people, the selfexcluders will be of an interest. Especially, when they face non-discretionary use.

According to Ipsos MORI (2015), 23\%, or an estimated 12.6 million adults in the UK, do not have the required level of basic digital skills. Another organization established to combat digital exclusion, reported that in 2014, 1.58 million small businesses and charities were excluded from online activities, whilst $11 \%$ of adults (5.9 million) have never used the Internet (GO-ON UK, 2016). Furthermore, these trends appear to be echoed by another investigation, conducted by Oxford Internet Survey (Dutton, Blank \& Groselj, 2013). According 
to this research, Internet use in Britain among adults who are over 44 years' old peaks at $85 \%$ (age group 45-54), fall and reaches $39 \%$ in the age group above 65.

This data prompted an investigation of what happens when those uninvolved with technology face its non-discretionary use.

There are a number of studies undertaken in a variety of similar topics, some of them going all the way back to technology acceptance in the workplace (Davis, 1989) or easing the way in which technology is introduced to people (e.g. Tornatzky \& Klein, 1982). More recent examples include universal design (e.g. Stephanidis, 2009), or an issue of digital divide (Pick \& Azari, 2007, McKey, 2005, Hongladarom, 2004). There was a study conducted by Satchel and Dourish (2009) concerning use and non-use in $\mathrm{HCl}$, as well as set of studies in the Information Systems field describing discretionary and non-discretionary use of technology on organisational level (Chae \& Poole, 2005, Sorebo \& Eikebrokk, 2008).

Brown, Massey, Montoya-Weiss \& Burkman (2002) define non-discretionary use as one in which users are required to use a specific technology or system in order to keep and perform their job. Ahmad \& Basden (2008) distinguish between nondiscretionary use (NDU) and discretionary use (DU); whilst the former indicates that the information system must be used whether its users want it or not, the latter grants the decision to the user. However, there seems to be no equivalent studies of people and non-discretionary use of digital technology in everyday settings.

This paper will aim to investigate those who decided to either exclude themselves (or have been excluded) from the digital world (or just some parts of it), who now, due to particular circumstances are obliged to change their attitudes. The so-called "non-discretionary" use will be understood as use not of one's own volition. It is obligatory, mandatory, not subject to one's preference and judgement. It will refer to circumstances in which a user is facing an unwanted interaction; however, the general cost of rejecting the technology is greater than the personal cost and consideration for own comfort.

This paper will argue that to consider this nuanced, unique context, the methods of investigation have to be suited to the type of participant. This will take form of methodological bricolage, tailored using a variety of qualitative research approaches.

\section{QUALITATIVE RESEARCH AND METHODOLOGICAL BRICOLAGE}

Qualitative research methods create an opportunity for a degree of flexibility within the studies, adapting to individual cases (Flick, von Kardorff \& Steinke, 2004). They allow (and to some extent encourage) employing a variety of data research perspectives. Combinations of different accounts complement each other and emphasise strong points, or, on the other hand, illustrate limitations of respective approaches.

Qualitative research practices make the world visible, turning it into collections of representations, whether these are field notes, interviews, recordings, photographs etc., but also the wide range of interconnected, interpretative practices allows the researcher to gain the best possible understanding of given phenomena. For example, he or she, may refer to numerous materials: case study, personal experience, introspection, life story, interview, artifacts and cultural texts, along with "observational, historical, interactional and visual texts - that describe routine and problematic moments and meanings in individual's lives" (Denzin \& Lincoln, 2011), as "each practice makes the world visible in a different way. Hence there is frequently a commitment to using more than one interpretative practice in any study" (Denzin \& Lincoln, 2003).

This leads us to the notion of bricolage. According to Oxford Dictionary, the term originates from French; it stands for construction or creation from a wide assortment of available things. Initially, anthropologist Lévi-Strauss (1966) brought up the bricolage metaphor in his pursuit of understanding human meaning-making. He specifically referred to societies embracing mythical rationalities, where "mythical-knowers piece together their life-history with artifacts (e.g., texts, discourses, social practices) of their given cultural context to construct meaning" (Rogers, 2012). Lévi-Strauss compares those practices to a process of bricolage, fluid, flexible, and open-ended. He describes a bricoleur as a "Jack of all trades or kind of professional do-ityourself person" (Denzin \& Lincoln, 2003), who uses whatever knowledge tools he or she have in their repertoire.

The idea was subsequently adopted as a means to conceptualize the eclectic nature of social inquiry (Rogers, 2012). Denzin and Lincoln (2003) encourage deploying a range of methodologies as well as theoretical perspectives derived from multiple disciplines, whilst Berry \& Kincheloe (2004) advocate to "make use of all the tools available to complete a task". However, as a methodological framework, bricolage is not widely applied in the field of $\mathrm{HCl}$. Thus, this paper attempts to introduce it as a reliable, consistent, and valuable method of investigation.

Rogers (2012), describes bricoleurs as "craftspeople who creatively use resources left over from other projects to construct new artifacts". They utilise materials and tools "ready at-hand", rather 
than following strict procedures, and applying specific tools; "within the domain of qualitative research it denotes methodological practices explicitly based on notions of eclecticism, emergent design, flexibility, and plurality". Bricoleurs are able to consider phenomena from various theoretical and methodological perspectives, which in some cases may compete with each other.

Furthermore, Denzin and Lincoln (2003) explain bricolage through the concept of montage, a method of editing cinematic images. In montage, a variety of imagery are brought together to create a picture. There are sequences of images built one upon another that allow viewers to interpret the scenes as they unfold. The notion behind montage is that viewers look at the arrangements not one after the other, but rather simultaneously, "The viewer puts the sequences together into a meaningful, emotional whole, as if in a glance, all at once". Producing bricolage can be also described with a number of other metaphors: weaving; sewing; quilting; montage; collage; "the fragments of data or different materials, can though, be thought of as either being drawn into an ordered whole $(. .$.$) or left disjointed and jarring against each$ other (...)" (Wibberley, 2012).

The methodological bricolage in particular, requires the bricoleur to engage in a number of diverse tasks, combining a variety of relevant tools, and applying creative approaches. These are "ranging from interviewing to intense self-reflection and introspection" (Denzin \& Lincoln, 2003). In active bricolage the researcher brings his or her understanding of research context and their previous experience of research methods together; "This allows bricoleurs to examine phenomena not as detached things-in-themselves, but as connected things-in-the-world" (Rogers, 2012).

Methodological bricolage is not the only instance of this procedure recognised by Denzin and Lincoln (2003). They describe interpretative bricolage, involving interpretative process that bring together sets of representations, tailored to the specifics of complex situation. In narrative bricolage, researchers tell stories about the worlds they have studied; objective reality can never be "captured"; research transcripts can only represent interpretations of phenomena. Theoretical bricolage includes a wide knowledge about multiple interpretative paradigms that can be applied to any given problem; researchers may work between or within competing and overlapping perspectives. Lastly, political bricolage recognises that science is a power, and research findings have political implications, as there is no such thing as value-free science.

The qualitative researcher who uses bricolage is able to put elements of reality together, bringing psychological and emotional unity to an interpretative experience.

Kincheloe, (2001) presents an argument that bricoleurs actively construct their research methods, rather than passively recreate existing methodologies. As a result, they embrace the complexity of relevant inquiry, and reject deterministic views of social reality. Bricoleurs become methodological negotiators, respecting the demands of the task, promoting its elasticity, and resisting its placement in concrete. A bricoleur should be aware of methods that exist, should devote time for rigorous investigation into current techniques, their application, as well as their relation to other procedures.

Understanding the specifics of this construction process helps multiperspectival researchers choose and develop the methodological, theoretical, and interpretative tools they need to address the depictions of the world that emerge from it. In the context of the philosophical inquiry as conceptual clarification, the bricoleur understands that the objectivist view of knowledge assumes that meaning in the world exists separately from an individual's experience. (Kincheloe 2001, p. 9)

Kincheloe emphasises that bricolage is not an "everything goes" approach aiding undecided researchers, but rather a lifelong commitment to applied knowledge and research expertise. A skilful bricoleur has a broad scope of relevant techniques that he or she can deploy in any given context, with appropriate rigour, recognising and working with its' complexities.

\section{NON-DISCRETIONARY USE OF DIGITAL TECHNOLOGY}

The context of non-discretionary use of digital technology is very particular - people are "thrown" into certain circumstances, and have limited opportunity to choose whether or not they wish to continue interacting with them. Over a period of time, their practices and everyday experiences are altered to accommodate the non-discretionary use. The research aimed to record a first-hand experience of this process. In order to achieve that, it required application of different methods, each tailored to a specific type of user under investigation.

The main objective of the studies was to create an engaged, first-hand, context dependent account of how people cope with digital technology in nondiscretionary context. Research perspectives include phenomenology (Dourish, 2001, Smith, Flowers \& Larkin, 2009), to pursue subjective meanings and individual outlooks; ethnomethodology (Garfinkel, 1967), to understand people's everyday practises; and hermeneutics (Robson, 2004) as a means of interpretation. The 
research relied upon a bricolage of qualitative methods of data gathering, which enables open and involved investigation, as well as interpretive methods to make sense of gathered information.

\subsection{Bricolage of Methods}

Empirical investigation involved a bricolage of qualitative data-gathering techniques. These consisted of participatory observation, semistructured interview, as well as content and thematic analysis. Although applied methods differed between each study, they were subsequently subject to the same process of Interpretative Phenomenological Analysis (Smith, Flowers \&Larkin, 2009), to maintain methodological rigour. The choice of techniques was very important due to the particular context of respective investigations. Each of them matched the type of user under investigation. In result, the bricolage of methods enabled viewing the subject from multiple perspectives.

Three studies were designed to investigate the phenomenon of non-discretionary use. These included:

(i) Lucy and the Wind, an ethnographic study involving observation of a novice consumer of a digital technology

(ii) Where the Wild Things Are, a thematic analysis of online platforms

(iii) C's Castle, semi-structured interview with a self-proclaimed technology expert

The novice user was a person with no experience with digital technology, having no preconceptions, knowledge or vocabulary to communicate about it. Conducting an interview in these conditions appeared futile. There was no shared understanding of the issues in question. Hence, the primary method of inquiry was a participatory observation (Robson, 2004) and so-called "thinking aloud" (Nielsen, 1993). This allowed recording the activities, opinions, and emotions experienced by the participant.

Table 1: Data collection schedule for Lucy and the Wind study

\begin{tabular}{|c|c|}
\hline $\begin{array}{l}\text { Primary data gathering } \\
\text { method }\end{array}$ & Data collection \\
\hline $\begin{array}{l}\text { Participatory } \\
\text { Observations }\end{array}$ & $\begin{array}{l}3 \text { weeks: } \\
7 \text { sessions in total (up to } \\
3 \text { sessions per week), } \\
1-3 \text { hours each }\end{array}$ \\
\hline $\begin{array}{l}\text { Observation using } \\
\text { TeamViewer }\end{array}$ & $\begin{array}{l}6 \text { weeks: } \\
1 \text { session weekly, } \\
1-2 \text { hours each }\end{array}$ \\
\hline User Reporting & $\begin{array}{l}15 \text { months: } \\
\text { Irregular, unstructured } \\
\text { conversations }\end{array}$ \\
\hline
\end{tabular}

The motivation behind second study was to uncover whether the non-discretionary use of digital technologies occurs "in the wild", among online contributors and, if so, how they learn to cope with it. Primarily, individual comments, blog entries, and forum posts were analysed. It was important from the perspective of the research to keep the investigated material subjective, based on personal opinions of the users, rather than on opinions from professional writers (including specialised technology commentators and scientists).

Table 2: Range of online resources for Where the Wild Things Are study

\begin{tabular}{|l|r|}
\hline Resource & Number of pages \\
\hline Online forums & 15 \\
\hline Blog entries & 17 \\
\hline Online project support & 2 \\
\hline Online articles & 20 \\
\hline$\quad$ Total & 54 \\
\hline
\end{tabular}

Resources were subjected to a thematic analysis (Braun \& Clarke, 2006). A snowball sampling (Robson, 2004) was applied to find relevant resources.

Third study, "C's Castle" was chosen as a sharp contrast to the previous investigations, to research whether a self-proclaimed technology expert also experiences non-discretionary use. The user was knowledgeable, well-spoken and had extensive knowledge of the domain. This allowed a level of independence regarding the direction of narration, and produced unrestricted answers. He was examined using a semi-structured interview (Robson, 2004). Initially the participant was prompted simply to describe his relationship with the digital technology, and subsequently in depth questions were asked to fully understand his narrative.

\subsection{Interpretative Phenomenological Analysis}

To sustain consistency and investigative rigour, each study was subject to a process of Interpretative Phenomenological Analysis (IPA) used to examine gathered information. This research approach enabled obtaining a detailed description of an everyday experience, as the involved individual perceives it (Smith et al., 2009).

Smith et al. (2009) provides a thorough, systematic description of conducting an IPA study, including the process of research design, implementation 
and finally analysis of gathered data and writing-up the findings. There are several steps to follow whilst engaging with the IPA approach, which were subsequently applied within this project. These include:

\section{(iv) Reading and re-reading}

(immersing oneself in the data)

(v) Initial noting

(examining semantic content and language use)

(vi) Developing emergent themes

\section{(vii) Searching for connections across emergent themes \\ (viii) Moving to the next case \\ (ix) Looking for patterns across the cases}

Interpretative Phenomenological Analysis is an approach designed to point a phenomenological investigator towards available solutions and procedures that allow gaining a comprehensive, rich analysis of gathered data. The suggested methods allow developing a deep, consistent, sophisticated, and nuanced account.

\section{3 "Lucy and the Wind": Study of Technology Novice}

Lucy and the Wind was an ethnographic study of a novice consumer of a digital technology. The volunteer, a 54 year old female small business owner, was chosen due to her unique settings. Having a family member abroad, Lucy regularly spent money on phone calls. Changes in personal circumstances led her to financial difficulties, and further, prevented her from staying in touch with her daughter. As a solution, she received a gift netbook computer (MSI Wind), and was encouraged to use Skype as a means of communication. Her motivation to remain in contact with her child allowed Lucy to overcome the fear of using digital technologies, and to begin her relationship with the device.

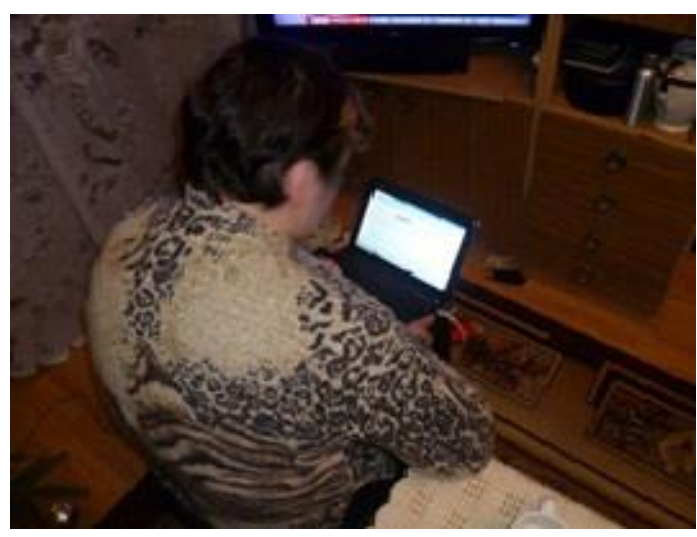

Figure 1: Lucy using Facebook on MSI Wind
Lucy had very little previous experience with technology in general, and a nearly complete lack of preconceptions/familiarity with most modern digital devices. Working as a shop owner, Lucy was used to simple menu based appliances including a cash register and a mobile phone.

To put the concept further into perspective: during initial observation, it became apparent that Lucy not only had no understanding of the desktop metaphor, but she also did not have an understanding of usual desktop features including folders, toolbars, Internet browsers etc. The concept of selecting and opening a programme by clicking the icon was non-existent. For Lucy the PC desktop was merely an image, and the accompanying icons, folders shortcuts etc., a part of a general picture, rather than independent elements with the prescribed qualities, affording certain interactions. The notion behind the project was to follow the participant's activities during her initial and subsequent interactions with the available technology, to record her actions, her reactions to different situations and expressed emotions. The types of observed interactions included:

- Switching computer on and switching it off

- Learning to use keyboard

- Learning what the desktop is

- Learning what the icons are

- Learning to operate Internet browser

- Supervised and unsupervised use of Facebook

- Supervised and unsupervised use of Skype

- Supervised and unsupervised use of Google search engine

The supervised interactions were supported and guided by Lucy's more knowledgeable friend, who would provide a step-by-step descriptions of each interaction, as well as set up the software. The "tutor" was a neighbour of Lucy's, a woman only six years younger, however much more versed in using digital technology.

There was a strong evidence of a non-discretionary use of the digital device, as the initial interaction with her device was postponed for over two years, and when it occurred, it was due to external pressure. However, this attitude has changed with time; with the development of new skills, and further benefits of the technology discovered by the participant, the motivation to use the device changed as well. Lucy was initially motivated by the financial aspect, however with time this would evolve into a self-improvement exercise, a status symbol, and social activity.

Particularly the social aspect served both as a coping strategy (relying on other people to provide 
tutorials, to create accounts, to apply solutions to occurring issues), as well as motivation (being able to communicate via Skype and Facebook, or to have an invented rivalry with her spouse (who was not a technology user at all).

As the novice user, she did not attempt any customisation and personalisation of her devices, nor online profiles. Lucy would not create content and would remain a passive consumer. She would not engage (nor understand) Google search as a source of solutions, nor attempt trial and error.

Engaging with a novice user can be described as both interesting and disappointing. After the initial tutorials and learning process, the user acquired a basic skillset allowing her to operate the device. Furthermore, computer-related vocabulary became a frequent occurrence in her everyday conversations, and online experiences became subjects of casual discussions. This indicates changing everyday practices. However, the subsequent interactions became repetitive, with very few new skills being considered.

\section{4 "Where the Wild Things Are": Study of Online Communities}

The study of online communities was inspired by consultations with local digital initiatives. Each of them were approached and in informal conversations a brief scope of their activities was discussed, including the problem of dealing with non-users, everyday struggles of users with low technological skillsets and foremost, issues of how to change people's perception of the technology all together.

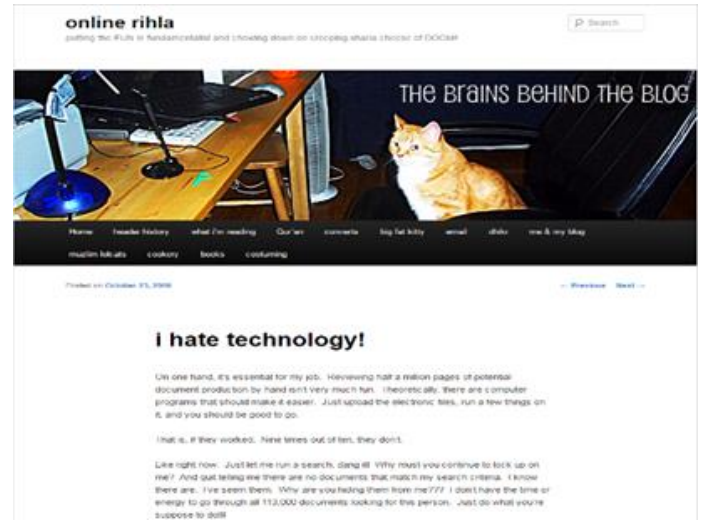

Figure 2: Example of online blog

This was particularly relevant, when changing circumstances would force people to adjust their everyday practices, including pressure from family members, financial issues, technological change within current employment, or change of occupation all together. Volunteers who provide technical support to technology novices suggested several resources that were popular among their learners. The recommendation was to investigate online communities of users searching for advice (or sometimes expressing their discomfort, disenchantment, frustration) via online platforms.

There was strong evidence among the general public that involvement with digital technologies became unavoidable. There were numerous posts describing nostalgia for "good old times", when technology was less overwhelming; furthermore there were frequent entries complaining about its increasing complexity.

I hate how everyone is glued to Facebook, and it's spring but no one is outside. I don't ever visit my friends anymore, and even if I did, they are so absorbed into their texting touch-screens that it is pointless. I miss talking on my bulky home phone, writing letters, and playing endless games of Monopoly with my friends. Now it is all over. Do you think my future is a bleak as I make it out to be?

Technology was associated with a sense of anxiety, and reflected upon with sour disillusionment. Despite these apprehensions, users would remain technology consumers; some of the reasons included being mocked and singled out among their peers. However, for each of these negative comments there would be a counterargument from technology enthusiasts, who would argue benefits of digital involvement.

\begin{abstract}
Nevertheless the more advanced we get the better our chances of living in an eco-friendly healthy society will be, just look at wind farms, solar power and cancer research! Technology has given us the gift of communication, internet, transportation, entertainment, I could make a very long list but I won't bore you. My point is you should embrace what it has given us and will continue to give us. But once again you are not alone, and people will continue to have quiet settlements away from urban technological areas.
\end{abstract}

The sole act of posting their own concerns on Internet forums could be interpreted as a coping strategy. Users would often seek their peers' opinions and advice to improve the learning process. This further indicates the significance of social aspects in this context. Other strategies include review of online tutorials and trial and error.

\footnotetext{
I have several tutorials open in my browser and each one I picked up to understand the tutorial that came before it.: How to load music to my phone, how to sync my phone, how to format the memory card. This is ridiculous. All for 40 seconds of music that nobody but me cares about. And yet, I have to win
}

Online contributors often referred to breaks in interactions with technology. They listed usability and user experience related concerns. Unlike novice user before, they would often describe 
activities involving customisation and personalisation.

\section{5 "C's Castle": Study of Self-Proclaimed Expert}

"C" was a 23 years old psychology graduate, looking for a job. The participant described himself as middle class; both his parents occupy managerial positions.

Initially it may appear to be a counterintuitive exercise to pursue someone who would describe himself as an "expert". Gaining expertise within a subject area requires extensive engagement, motivation and commitment, and may be interpreted as the exact antithesis of nondiscretionary use. However, from the perspective of sound and illustrative research, it was important to present a variety of points of view.

The three main areas of interest investigated during the interview, included general attitude towards technology (to uncover the context); questions of non-discretionary use, and whether it can be a significant issue for those who are already proficient with the technology; and a query concerned with everyday interactions with digital technologies. During each narrative, additional questions were asked if necessary.

"C" admitted to having widespread knowledge of digital technologies and described himself as a "gamer". He was able and quite comfortable with a wide variety of digital skills, including being able to build his own machine, network all his appliances and to fix/install computer components, for instance changing a graphic card or other elements of the motherboard in his machine.

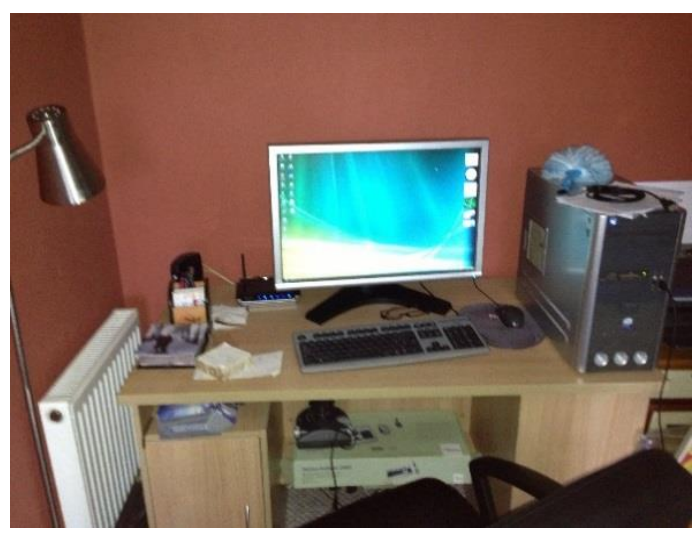

Figure 3: "C"'s PC setup

"C" has shown that despite his knowledge and understanding of technology, he also faces nondiscretionary use. He described the necessity of learning some of the software (for example the MS Office package), and involvement with digital devices in general, as unavoidable.
(...) if you are trying to find a job and that is the only way to do it you just have to sort of knuckle down and learn how to do things. Makes you jump through a couple of hoops. I can't think of any other times where l've had to use it and there is no alternative. Sometimes you just have to do what you can to learn to use it and that it goes ok.

"C" proved to be inquisitive and resourceful and foremost interested in this field. He would seek understanding and follow professional literature. Although his motivations would include better employment, he also shown an overwhelming concern of falling behind.

(...) I think I, I think I would, yeah if it wouldn't be for job, I probably would still want to learn more about them. And try and you know, move along with the technology. Because you don't want to be left behind, that sort of thing, it's always kind of rubbish (...) । think it's extremely difficult in this day to like to avoid technology. You know, unless you live in a cave and genuinely have no way of doing it. It is pretty much impossible to avoid it. Amm... so, partly the necessity to... you got to keep in touch...

In the same way as a novice user, "C" also appreciated the social aspects as a coping strategy. On many occasions he referred to his friends as important assets in the learning process. Unlike the novice, however, he would also make his own attempts to resolve any arising issues, whether by searching for solutions online or by consulting the manual.

The participant appeared genuinely interested and honest in his responses; after the interview he admitted that he may be re-thinking his general attitudes and everyday practices in relation to digital technology.

And as soon as you take away something that they have been relying upon for so long, they just... people panic, the reason is, there is just stuff they can do themselves, but they just don't know how, because they rely on, they had the machines doing it for them for so long. Amm, yeah... I don't know, it is... I just worry that people will be too relying on technology that could break and especially when it is all networked together and when there is a potential for one part to go wrong and affect the rest of it.

"C" would also describe technology as often "alienating". He would nostalgically reminiscent about the times when his interactions with friends were simpler and more personal, rather than mediated via digital appliances.

Lastly, unlike the novice user, "C" reflected upon usability issues and negative user experience. He would point out flaws in online applications that often led to non-discretionary use. Similar opinions were found among online communities. 


\section{FINDINGS}

Knowing a wide context in which participants operate, being able to combine multiple perspectives, but also applying methods to suit the type of participant allowed gaining meaningful, context-dependent data and revealing respondents' everyday practices.

Two major findings included a detailed understanding of differences between the occurrences of non-discretionary use, as well as recognition of multiple mechanisms that allowed users to cope with those specific circumstances.

\subsection{Distinctions of Non-Discretionary Use}

First of all, a nuanced understanding of nondiscretionary use was recognized as a mechanism working in two directions:

(i) Non-discretionary to discretionary: occurring when users start familiarizing themselves with the respective systems, they recognize benefits of the initially unwanted interaction.

(ii) Discretionary to non- discretionary: occurring due to outside pressure, negative experiences, additional interactions, including updates, downloads, and extensions etc. that were not welcomed.

In "Lucy and the Wind", the initial premise was to investigate a user who interacted with technology not of their own volition, but rather due to specific circumstances she found herself in. For Lucy it was an effect of financial implications of communicating with a family member abroad. Initially the experience resulted in a variety of negative experiences; these included fear, anger, anxiety and lack of understanding. However, with time she started familiarising herself with the respective systems; she recognised benefits of the initially unwanted interaction. With time she went beyond what was expected of her. Lucy progressed from interacting with a single piece of software (Skype), to using a social networking site (Facebook), and Internet search engine (Google), and streaming content. She went even further to voluntarily purchase next generation hardware to improve her interactions. In both cases there was a noticeable transition from non-discretionary to discretionary use.

In contrast, "C"'s Castle and "Where Wild Things Are" showed transitions that appear to be reversed. Initially "C" described himself as a technology expert, he talked extensively about his technological prowess and widespread interactions. However, with time and after further reflection he started to open up. He admitted that among systems he is using there are some he intentionally avoided (MSWord), as they would associate him with a career path he did not want to pursue. Yet due to outside requirements he had to change his attitude and learn them reluctantly. Furthermore, due to negative experiences with online resources (banking website) he purposefully started avoiding subsequent interactions and only engaged with the system if absolutely necessary.

Similarly, online users often followed this reversed trend. Initially they would mention software and hardware used willingly, however often it would be associated with additional interactions, including updates, downloads, extensions etc. that were not welcomed. Again, in this case users retreated from initial voluntary experience into unwanted interaction, or in other words transition from discretionary to non-discretionary use.

\subsection{Coping Mechanisms}

Secondly, the research has shown that regardless of the level of technical knowledge, all types of users experience non-discretionary use, and all develop an assortment of strategies in order to manage it, including:

(i) Personal benefits: strategy consists of benefits that the user can recognise as immediately relevant; they refer to users' actual plans and actions

(ii) Negotiated benefits: strategy consists of transferable skills in combination with an "if" statement ("if" this happens, I will use it); the "if" statement may be hypothetical, it does not need to relate to users' actual plans and actions

(iii) Trial and error: strategy consists of continuous interaction until the right solution is discovered

(iv) Familiarity: strategy consists of a level of know-how and recognition

(v) Fun and pleasure: strategy consists of adding the value of positive and enjoyable activities to enhance the experience

(vi) Competition: strategy consists of real or invented competition with other users and/or the technology itself

(vii) Anthropomorphisation: strategy consists of attaching human characteristics to inanimate objects

Across the studies, users revealed employing familiarity, fun and pleasure, and a range of personal and (or) negotiated benefits in order to learn to cope. However, the novice would not engage in trial and error activities (fearing being unable to recover from mistakes), whilst the "expert" and the public, would refer to problems 
with usability and user experience as obstacles in discretionary use.

Initially, Lucy displayed strong feelings of anxiety, however, with time, due to recognised personal benefits; she developed a very encouraged, excited outlook. This changed her motivation completely. Lucy embraced the personal benefits of engagement with both hardware and software; she was showing off her skills and treating them as a status symbol. There was, however, no strong evidence of negotiated benefits in Lucy's experience. It could be due to the novice user not having enough knowledge in order to recognise transferable skills. Although there was evidence of the "if" statement, particularly in reference to the temporal dimension ("If I had more time...").

In the online study, both types of users, enthusiasts and sceptics, expressed themselves in an emotional manner. The tone of online posts had a strong sense of anger and fear, particularly amongst those users who felt overwhelmed with technology and perceived it as inescapable; some expressed sadness and nostalgia in regards to the past, less technologically-oriented times, whilst others enjoyed the benefits and opportunities the current context creates. There was evidence of fun and pleasure derived from interaction with technology, yet there was not much mention of anthropomorphisation. Further strategies included trial and error as well as familiarity, but also activities, including searching through forums and tutorials. The fact of engaging in online discussions with peers implies social aspects of the experience.

Despite describing himself as an "expert" user, "C" revealed that not all of his interactions with digital technology were voluntary. He would refer to services and packages he used with an underlying sense of non-discretionary use. In those instances, motivation proved to be a strong driving force behind his actions. He reflected upon the personal benefits of using gained knowledge and skills in order to get better employment. "C" claimed that to take full advantage of the benefits of technology, he would not hesitate to change his everyday practices. He also mentioned negotiated benefits, with the "if" statement involving an enhancement of service ("If they would make it better, I would use it"). This adds another layer of understanding to this theme, as he described desired improvements in reference to changing the usability and user experience. Lastly, there were strong social aspects reported in "C"'s coping strategies, as he relied often on his more knowledgeable friends to help him with arising technical issues. This is a strong theme joining all of the studies: in each case the social aspect made a significant difference, encouraging participants to embrace the unwanted interactions.

\section{DISCUSSION}

The aim of this research was to uncover subjective, individual experiences and everyday practices of various respondents who happen to be exposed to a certain context. Each study had a unique setting, and particular type of respondents, whose everyday interactions with digital technologies varied significantly. Applying methodological bricolage allowed tailoring techniques in order to provide the most valuable results for each investigation.

\subsection{The Risks and Returns of Bricolage}

The use of bricolage comes with both positive and negative implications. However, conducted appropriately and analysed consistently, it proves to be an efficient and effective methodology.

\subsubsection{The Risks}

Initially, the notion of arbitrarily choosing research methods may feel intimidating. The researcher trained in rigorous research procedures needs to overcome the sense of being disloyal to well established methodological conventions. He or she may question the validity of their own approach, and further, may be apprehensive whilst seeking approval from peers. Is this approach scientific? Is data reliable? Is the research replicable? Should it be? Dealing with nuanced experiences of individuals facing unusual circumstances is not a textbook occurrence; it requires deep understanding and a personal approach, whilst simultaneously sustaining a professional distance and objectivity. It requires confidence, skills and trust in one's own abilities to continue. Bricolage may be perceived as a domain of social scientists and designers, however it proves to be highly appropriate for the $\mathrm{HCl}$ community.

\subsubsection{The Returns}

From the perspective of a researcher venturing into unknown, or sometimes hostile territory, for instance that of non-discretionary users, who may be unsure, anxious or disillusioned with technology, there is a need for a sensitive, engaged and inviting methodology. Bricolage allows this subtle, involved approach, it enables creation of bespoke frameworks that fit both research narrative, but also actively encourage participants to contribute their knowledge and experiences. It would be difficult to expect a novice to be able to speak about the subject matter with the same knowledge and understanding as an "expert" user. The research context proves to be stressful enough. Should novice be asked to provide an extensive narrative, it might in effect bring no data at all. Furthermore, hidden behind a veil of anonymity, online contributors may feel inspired to provide random, if 
not dishonest answers. Thematic analysis of already existing resources revealed that the phenomenon of non-discretionary use is present on a wider scale.

The combination of those multiple perspectives contributed towards better understanding of the phenomenon of non-discretionary use, as well as generating a list of shared strategies utilized by the participants. Application of methods tailored to specific users allowed to uncover strategies that otherwise could be missed. For instance, the novice user did not incorporate trial and error into her practices, due to concern that she would not be able to recover from possible errors. This was apparent during the observation; however, Lucy was too embarrassed to admit it verbally. Similarly, the observation exposed a role of competition in the process. This appeared to be a strong motivational strategy for the novice user, however she seemed unaware of it, and it was only apparent when observing Lucy's interaction with her spouse.

In contrast, observing " $C$ " in his everyday setting brought an image of confident, knowledgeable, well-prepared technology user, whereas digging deep into his personal experiences, opinions, and concerns unravelled hesitation, sense of anxiety, and to some extent, disillusionment with digital technologies. Lastly, as online communities were available only virtually, it would be difficult to apply any of the previous methods in a reliable manner. However, analysing available resources brought diverse, meaningful picture of their experiences, burning concerns, and hope for resolution.

\subsubsection{The Devil in the Detail}

What made bricolage particularly effective, was combining it with Interpretative Phenomenological Analysis. The IPA is designed to point an investigator towards available solutions and procedures that allow gaining a comprehensive, rich analysis of gathered data. The suggested methods encourage developing a consistent, sophisticated, and nuanced picture of the phenomena. IPA actively supports the researcher, to derive meaning from everyday activities and situations. Employing IPA to analyse a variety of methods dealing with the particular manifestation of peoples' experiences with non-discretionary use allowed producing sets of descriptive, valuable, and reliable data. On its own each method allowed gaining deep and detailed understanding of a different type of user connected only by specific circumstances they found themselves in. Collectively, they allowed creation of a strong, engaged platform to research such a sensitive subject as people's personal experiences with digital technologies, particularly within a nondiscretionary context.

\section{CONCLUSION}

There was a strong relationship between chosen methods and the produced results. Deploying bricolage as a method of qualitative inquiry allowed to understand the phenomenon of nondiscretionary use in the best possible way, as it employed a variety of investigative techniques, each uncovering a different aspect of the examined world. It allowed obtaining reliable, contextdependent knowledge, and to view phenomena as connected things-in-the-world. Combined with consistent, well-structured, method of Interpretative Phenomenological Analysis, it has provided reliable results. Bricolage if undertaken rigorously could be a valuable addition to $\mathrm{HCl}$.

\section{REFERENCES}

Ahmad, H., \& Basden, A., (2008). NonDiscretionary Use of Information System and the Technology Acceptance Model, in Annual IRIS Conference, 2008, University of Salford, Salford.

Braun, V., \& Clarke, V., (2006) Using Thematic Analysis in Psychology. Qualitative Research in Psychology, 3 (2). pp. 77-101.

Brown, S. A., Massey, A. P., Montoya-Weiss, M., \& Burkman, J., (2002). Do I Really Have to? User Acceptance of Mandated Technology. European Journal of Information Systems, 11, pp. 283-295.

Chae, B., \& Poole, M. S., (2005) Mandates and Technology Acceptance: A Tale of Two Enterprise Technologies. Journal of Strategic Information Systems, 14, pp. 147- 166.

Davis, F., D., (1989) Perceived Usefulness, Perceived Ease of Use, and User Acceptance of Information Technology, MIS Quarterly, 13(3), pp. 319-340.

Denzin N., K., \& Lincoln Y., (2003) (Eds.) Strategies of Qualitative Inquiry, (2nd ed.), Thousand Oaks, London, New Delhi, Sage Publications.

Denzin, N., \& Lincoln, Y., (Eds.) (2011). The SAGE Handbook of Qualitative Research (4th ed.). Thousand Oaks, CA: Sage.

Dourish, P., (2001) Where the Action Is. Cambridge, MA: MIT Press.

Dutton, W., H., Blank, G., \& Groselj, D., (2013) Cultures of the Internet: The Internet in Britain. Oxford Internet Survey 2013. Oxford Internet Institute, University of Oxford.

Flick, U., von Kardoff, \& Steinke, I., (Eds.) (2004) A Companion to Qualitative Research, London, Thousand Oaks, New Delhi, Sage Publications.

Garfinkel, H., (1967). Studies in Ethnomethodology. Polity. 
Go-On UK. Retrieved August 2016, form http://www.go-on.co.uk

Hongladarom, S., (2004) Exploring the Philosophical Terrain of the Digital Divide, Australian Computer Society, Computing and Philosophy Conference, Canberra, Conference in Research and Practice in Information Technology, Vol. 37, pp. 85- 89.

Ipsos MORI (2015) Basic Digital Skills, UK Report 2015, June 2015.

Kincheloe, J. L., (2001) Describing the Bricolage: Conceptualizing a New Rigor in Qualitative Research. Qualitative Inquiry, 7(6), pp. 679-672.

Kincheloe, J. L., (2004) Introduction: The Power of the Bricolage: Expanding Research Methods. In J. L. Kincheloe \& K. S. Berry (Eds.), Rigour and Complexity in Educational Research: Conceptualizing the Bricolage (pp. 1-22). Maidenhead: Open University Press.

Lévi-Strauss, C., (1966) The Savage Mind. Chicago, IL: University of Chicago Press.

McKey, E., (2005) Human-Computer Interaction Closes the Digital Divide: A Multicultural, Intergenerational ICT Case Study, South East Asia Regional Computer Confederation (SEARCC) 2005: ICT: Building Bridges Conference, Sydney, Australia. Conferences in Research and Practice in Information Technology, Vol. 46.

Nielsen, J. (1993) Usability Engineering, Academic Press, San Diego, CA.
Pick, J., B., \& Azari, R., (2007) Worldwide Digital Divide: Influences of Education, Workforce, Economic, and Policy Factors on Information Technology, SIGMIS-CPR'07, April 19-21, 2007, St. Louis, Missouri, USA.

Robson, C., (2004) Real World Research, (2nd ed.), Oxford: Blackwell.

Rogers, M., (2012) Contextualizing Theories and Practices of Bricolage Research. The Qualitative Report, 17(T\&L Art, 7), pp. 1-17.

Satchell, C., \& Dourish P., (2009) Beyond the User: Use and Non-Use, OZCHI, 2009, Nov. 23-27, 2009, Melbourne, Australia, pp. 9-16.

Smith J., A., Flowers, P., \& Larkin, M., (2009) Interpretative Phenomenological Analysis. Theory, Method and Research. SAGE, Los Angeles, London, New Delhi, Singapore, Washington DC.

Sorebo, O., \& Eikebrokk, T. R., (2008). Explaining IS Continuance in Environments Where Usage is Mandatory. Computers in Human Behavior, 24(5), 2357-2371.

Stephanidis, C., (2009) The Universal Access Handbook. Taylor and Francis.

Tornatzky, L., G., \& Klein, K. J., (1982) Innovation Characteristics and Innovation AdoptionImplementation: A Meta-Analysis of Findings. IEEE Transaction on Engineering Management, 29(1), pp. 28-45.

Wibberley, C., (2012) Getting to Grips with Bricolage: A Personal Account. The Qualitative Report, 17(Art. 50), pp. 1-8. 